\title{
NOTICE
}

\section{Confidential Awards Committee: ‘Best Paper' Prize(s) for 1991}

$\mathrm{F}$ aithful readers of Environmental Conservation will no doubt recall that, in an Editorial Notice published in 1985 (on page 292 of Volume 12, No 4), it was announced that the Foundation for Environmental Conservation hoped to institute a yearly 'Best Paper' Prize of not less than 1,000 Swiss francs [the then approximate equivalent of US $\$ 500$ but considerably more now] for the best paper or other contribution published either in the preceding year's volume of this its Journal or as a Chapter or Section of a book in either of its sponsored series or its Conference Proceedings. The confidential Foundation Awards Committee was asked to bear in mind the following as guidelines in making their selections: (a) most significant advance, (b) greatest potential influence for environmental good, and (c) quality of presentation.

For 1991 the wealth of truly excellent papers in Volume 18 of the Journal, on practically all aspects of environmental conservation, made the Committee's task exceedingly difficult.

With the agreement of the Foundation, and through its generosity in yet again adding very substantially to the announced minimum overall value of the prize, it has been decided that, bearing in mind the above guidelines (a)-(c), the 1991 prize should be shared equally between Dr Rohana Ulluwishewa for her paper entitled 'Modernization versus Sustainability: Disintegrating Village Agro-ecocomplexes in the Dry Zone of Sri Lanka' (Environmental Conservation, 18(2), pp. 103-9, with 5 figures), Dr W. Douglass Shaw for his paper entitled 'Environmental Economics: Can Economics Help Mother Earth?' (Environmental Conservation, 18(3), pp. 237-42), Professor Richard W. Butler for his paper entitled 'Tourism, Environment, and Sustainable Development' (Environmental Conservation, 18(3), pp. 201-9, with 1 figure and 2 tables), and Dr John Schelhas for his paper entitled 'A Methodology for Assessment of External Issues Facing National Parks, with an Application in Costa Rica' (Environmental Conservation, 18(4), pp. 323-30, with 5 figures).

The Committee is again heartened to record its unanimous opinion that the Journal publishes papers of an exceptionally high standard and accomplishes its stated objectives with admirable success. Indeed, with its additional 5 regular sections, Environmental Conservation seems to us clearly the leading Journal in its wide and vital field.

Chairman of the Foundation Awards Committee Environmental Conservation (C/O THE PUBLISHERS) 